\title{
HAMODYNAMIC ALTERATIONS INDUCED BY ISOPRENALINE IN PATIENTS WITH OBSTRUCTION TO RIGHT VENTRICULAR OUTFLOW
}

\author{
BY \\ DEAN T. MASON, EUGENE BRAUNWALD, AND JOHN ROSS, JR. \\ From the Cardiology Branch, National Heart Institute, Bethesda, Maryland, U.S.A.
}

Received April 26, 1965

It is now well established that there are two fundamentally distinct types of obstruction to left ventricular outflow, the first resulting from a discrete, fixed narrowing at a valvular, supravalvular, or subvalvular level, and the second being produced by muscular hypertrophy in the left ventricular outflow tract. A number of designations, including obstructive cardiomyopathy (Goodwin et al., 1960) and idiopathic hypertrophic subaortic stenosis (IHSS) (Braunwald et al., 1960) have been applied to the latter condition. In patients with the discrete forms of obstruction to left ventricular outflow, the area of the stenotic outflow orifice remains constant during hæmodynamic interventions which alter the systolic volume or the contractile state of the ventricle (Braunwald and Ebert, 1962), while with IHSS variations in the severity of obstruction may be induced by a variety of physiological and pharmacological stimuli. The dimensions of the obstructing orifice are not fixed in IHSS and the size of the left ventricular outflow tract varies, depending upon the contractile state of myocardium, the venous return, the systemic arterial pressure, and the systolic distending pressure (Whalen et al., 1963; Krasnow et al., 1963; Goodwin et al., 1964; Wigle, 1964).

Although obstruction to right ventricular outflow is most commonly of the fixed type, in this chamber the obstruction may also result entirely from subvalvular muscular hypertrophy. The latter type of obstruction was first recognized in patients in whom the muscular hypertrophy developed as a result of severe valvular obstruction, and became unmasked by effective surgical treatment of the primary lesion (Kirklin et al., 1953; Brock, 1955). More recently, muscular obstruction to right ventricular outflow has also been found to occur in the absence of treated valvular pulmonary stenosis, accompanying IHSS in some instances, or occurring in patients with idiopathic right and left ventricular hypertrophy unaccompanied by obstruction to left ventricular outflow (Braunwald et al., 1964; Taylor, Bernstein, and Jose, 1964).

The infusion of isoprenaline (isoproterenol), a drug that exerts a powerful stimulating action on the contractile state of the myocardium, either intensifies or provokes obstruction to left ventricular outflow in patients with IHSS, and measurement of the hæmodynamic response to this drug provides a useful test for detecting dynamic obstruction to left ventricular outflow (Braunwald and Ebert, 1962; Whalen et al., 1963; Krasnow et al., 1963). This observation suggested that study of the response of the right ventricular outflow tract to isoprenaline might allow differentiation of the fixed from the dynamic forms of right ventricular outflow obstruction, and provided the basis for the present investigation.

\section{Subjects AND Methods}

The 23 patients studied were divided into 3 groups. Group I consisted of 11 patients considered to have idiopathic hypertrophic subpulmonary stenosis. This group contained patient R.B., the only patient in the 
series who exhibited no hæmodynamic evidence of obstruction to right ventricular outflow in the basal state, but who developed a subvalvular systolic pressure gradient during isoprenaline infusion. Of the 11 patients in group I, 6 also had findings considered typical of IHSS with obstruction to left ventricular outflow in the basal state, the diagnosis in each patient having been established by a combination of clinical, hæmodynamic, and angiographic techniques, as detailed elsewhere (Braunwald et al., 1964). Of the other 5 patients, 2 (M.K. and R.B.) had evidence of left ventricular hypertrophy, exhibited no pressure gradients in the left ventricular outflow tract in the basal state, but developed left ventricular obstruction during the administration of isoprenaline. The 3 remaining patients in group I had no evidence of left ventricular obstruction either in the basal state or after isoprenaline. Two of these patients (K.Y. and W.S.) had evidence of left and right ventricular hypertrophy on electrocardiographic and angiocardiographic study, and were members of families affected by IHSS. Patient R.F. had idiopathic left ventricular hypertrophy, demonstrated by left ventricular angiocardiography, without obstruction to left ventricular outflow.

Group II consisted of 6 patients who exhibited subvalvular obstruction to right ventricular outflow from 7 to 32 months after successful surgical relief of valvular pulmonary stenosis, and who were, therefore, considered to have secondary hypertrophic subpulmonary stenosis. Group III consisted of 6 patients with discrete obstruction to right ventricular outflow. Hæmodynamic studies and angiocardiography revealed that 3 of these patients had valvular pulmonary stenosis, while the other 3 had discrete congenital subvalvular stenosis with intact ventricular septa.

After a stable basal hæmodynamic state had been achieved, the right ventricular outflow pressure gradient was determined by withdrawing the catheter from the pulmonary artery into the right ventricle; the cardiac output was then measured by the indicator-dilution method. Following these observations the catheter tip was advanced again into the pulmonary artery and isoprenaline was infused at a dose ranging from 0.5 to $3.0 \mu \mathrm{g}$. $/ \mathrm{min}$. When a stable hæmodynamic state had been achieved during the infusion, pressures in the pulmonary artery and right ventricle, and the cardiac output, were remeasured. The effective orifice areas in the right ventricular outflow tract were calculated using the Gorlin formula (Gorlin and Gorlin, 1951). In 9 of the patients in group I the effects of isoprenaline on the orifice area of the left ventricle were also studied by recording left ventricular and systemic arterial pressures together with the cardiac output before and during the administration of the drug.

\section{RESULTS}

In each of the 11 patients with idiopathic hypertrophic subpulmonary stenosis (group I) it was observed that the right intraventricular peak systolic pressure gradient increased following isoprenaline, rising from an average level of 8 to $24 \mathrm{~mm}$. Hg. In patient R.B., in whom no pressure gradient was present in the basal state, a gradient of $21 \mathrm{~mm}$. Hg was induced with the drug. The cardiac output increased by more than 1.01 ./min. in 9 of these patients and showed little change in 2 (Table I). Since, in each patient in whom the cardiac output rose, the rise was proportionally less than the square root of the increase in the pressure gradient across the right ventricular outflow tract, the calculated effective orifice index decreased from an average of $2.34 \mathrm{~cm} .^{2}$ to $1.59 \mathrm{~cm} .{ }^{2}$ (Fig. 1-3). The obstruction to left ventricular outflow was intensified in 6 of the 9 patients in this group in whom the effects of isoprenaline on the left ventricular dynamics were studied. Isoprenaline did not induce a pressure gradient in the remaining 3 patients who had no obstruction in the resting state.

In the patients with secondary hypertrophic subpulmonary stenosis, the administration of isoprenaline resulted in an increase in the pulmonary outflow tract pressure gradient in all, from an average of 21 to $48 \mathrm{~mm}$. Hg, and in a rise in cardiac output in 5 of the 6 patients (Table II). As in the patients in group I, despite the increase in flow across the obstruction, the effective right ventricular outflow orifice area was reduced in each patient (Fig 4), falling from an average of 1.40 to $1.09 \mathrm{~cm} .^{2}$

The effects of isoprenaline in the patients with discrete valvular or subvalvular obstruction to right ventricular outflow (group III) differed from those observed in the first two groups of patients (Table III). Although the pressure gradient across the outflow tract increased in each patient, rising from an average of 40 to $57 \mathrm{~mm}$. $\mathrm{Hg}$, the flow across the obstruction was raised sufficiently to account for the increase in the gradient, and the calculated pulmonary outflow area did not change, the average value remaining constant at $0.64 \mathrm{~cm}^{2}$ (Fig. 5). 
TABLE I

Effects of Isoprenaline in Idiopathic Hypertrophic Subpulmonary Stenosis

\begin{tabular}{|c|c|c|c|c|c|c|c|c|c|}
\hline \multirow{2}{*}{$\begin{array}{l}\text { Patient } \\
\text { and } \\
\text { age (yr.) }\end{array}$} & \multirow[t]{2}{*}{ Condition } & \multirow{2}{*}{$\begin{array}{c}\text { HR } \\
\text { (beats/ } \\
\text { min.) }\end{array}$} & \multicolumn{2}{|c|}{$\begin{array}{l}\text { Syst. press. } \\
\text { (mm. Hg) }\end{array}$} & \multirow{2}{*}{$\begin{array}{c}\text { Peak } \\
\text { RV-infund. } \\
\text { grad. } \\
\text { (mm. Hg) }\end{array}$} & \multirow{2}{*}{$\underset{\text { (1./min.) }}{\mathrm{CO}}$} & \multirow{2}{*}{$\begin{array}{l}\text { Eff. RV } \\
\text { outflow } \\
\text { orif. } \\
\left(\mathrm{cm} .{ }^{2}\right)\end{array}$} & \multirow{2}{*}{$\begin{array}{c}\text { Peak } \\
\text { LV-BA } \\
\text { grad. } \\
(\mathrm{mm} . \mathrm{Hg})\end{array}$} & \multirow{2}{*}{$\begin{array}{l}\text { Eff. LV } \\
\text { outflow } \\
\text { orif. } \\
\left(\mathrm{cm} .^{2}\right)\end{array}$} \\
\hline & & & RV & Infund. & & & & & \\
\hline $\begin{array}{c}\text { R.E. } \\
32 \\
\text { J.E. } \\
36 \\
\text { I.H. } \\
19 \\
\text { M.K. } \\
51 \\
\text { S.H. } \\
24 \\
\text { R.B. } \\
29 \\
\text { K.Y. } \\
10 \\
\text { R.F. } \\
48 \\
\text { W.S. } \\
16 \\
\text { R.P. } \\
14 \\
\text { V.S. } \\
\text { 61 } \\
\text { Average } \\
\text { values }\end{array}$ & 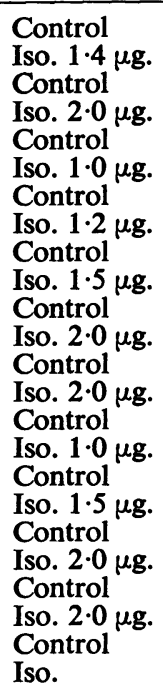 & $\begin{array}{r}68 \\
72 \\
90 \\
150 \\
78 \\
102 \\
84 \\
96 \\
72 \\
102 \\
84 \\
120 \\
90 \\
110 \\
84 \\
84 \\
84 \\
108 \\
66 \\
96 \\
78 \\
96 \\
80 \\
103\end{array}$ & $\begin{array}{l}41 \\
67 \\
36 \\
53 \\
42 \\
57 \\
38 \\
48 \\
37 \\
65 \\
32 \\
48 \\
26 \\
43 \\
30 \\
52 \\
36 \\
69 \\
28 \\
41 \\
35 \\
70 \\
35 \\
56\end{array}$ & $\begin{array}{l}15 \\
15 \\
30 \\
25 \\
39 \\
41 \\
32 \\
36 \\
32 \\
51 \\
32 \\
27 \\
23 \\
29 \\
18 \\
26 \\
30 \\
36 \\
23 \\
24 \\
18 \\
39 \\
27 \\
32\end{array}$ & $\begin{array}{r}26 \\
52 \\
6 \\
28 \\
3 \\
16 \\
6 \\
12 \\
5 \\
14 \\
0 \\
21 \\
3 \\
14 \\
12 \\
26 \\
6 \\
33 \\
5 \\
17 \\
17 \\
31 \\
8 \\
24\end{array}$ & $\begin{array}{r}6 \cdot 70 \\
7 \cdot 65 \\
5 \cdot 03 \\
7 \cdot 28 \\
4 \cdot 08 \\
9 \cdot 78 \\
6 \cdot 78 \\
9 \cdot 74 \\
4 \cdot 76 \\
3 \cdot 87 \\
5 \cdot 17 \\
8 \cdot 18 \\
3 \cdot 92 \\
5 \cdot 72 \\
5 \cdot 72 \\
6 \cdot 14 \\
9 \cdot 85 \\
11 \cdot 10 \\
4.96 \\
8 \cdot 61 \\
3 \cdot 42 \\
5 \cdot 12 \\
5 \cdot 49 \\
7 \cdot 56\end{array}$ & $\begin{array}{r}1.96 \\
1.46 \\
2.48 \\
1.91 \\
>3.00 \\
2.66 \\
2.24 \\
1.69 \\
2.31 \\
0.91 \\
>3.00 \\
1.90 \\
>3.00 \\
1.97 \\
1.86 \\
1.04 \\
>3.00 \\
2.02 \\
1.98 \\
1.27 \\
0.94 \\
0.63 \\
2.34 \\
1.59\end{array}$ & $\begin{array}{c}33 \\
49 \\
12 \\
55 \\
3 \\
63 \\
0 \\
53 \\
13 \\
79 \\
0 \\
41 \\
0 \\
0 \\
0 \\
0 \\
0 \\
0 \\
50^{*} \\
135^{*} \\
\frac{7}{7} \\
38\end{array}$ & $\begin{array}{r}1.89 \\
1.26 \\
1.30 \\
0.79 \\
>3.00 \\
1.66 \\
>3.00 \\
0.92 \\
1.17 \\
0.38 \\
>3.00 \\
1.59 \\
>3.00 \\
>3.00 \\
>3.00 \\
>3.00 \\
>3.00 \\
>3.00 \\
0.69 * \\
0.47 * \\
\overline{2.48} \\
1.73\end{array}$ \\
\hline
\end{tabular}

$\mathbf{H R}=$ heart rate, Syst. press.=systolic pressure, $\mathbf{R V}=$ right ventricle, Infund.=right ventricular infundibulum, $\mathbf{C O}=$ cardiac output, Eff. RV outflow orif.=effective right ventricular outflow orifice, $L V=$ left ventricle, $B A=$ brachial artery, Eff. LV outflow orif.=effective left ventricular outflow orifice, Iso.=isoprenaline and dose, $\mu \mathrm{g} / . \mathrm{min}$. *These values are not used in calculating average values.

TABLE II

Effects of Isoprenaline in Secondary Hypertrophic SubPulmonary Stenosis

\begin{tabular}{|c|c|c|c|c|c|c|c|c|c|c|}
\hline \multirow{3}{*}{$\begin{array}{c}\text { Patient } \\
\text { and age } \\
\text { (yr.) }\end{array}$} & \multirow{3}{*}{ Condition } & \multirow{3}{*}{$\begin{array}{c}\text { HR } \\
\text { (beats/ } \\
\text { min.) }\end{array}$} & \multirow{2}{*}{\multicolumn{2}{|c|}{$\begin{array}{l}\text { Syst. press. } \\
\text { (mm. Hg) }\end{array}$}} & \multirow{3}{*}{$\begin{array}{c}\text { Peak } \\
\text { RV-infund. } \\
\text { grad. } \\
\text { (mm. Hg) }\end{array}$} & \multirow{3}{*}{$\underset{(1 . / \mathrm{min} .)}{\mathrm{CO}}$} & \multirow{3}{*}{$\begin{array}{l}\text { Eff. RV } \\
\text { outflow } \\
\text { orif. } \\
\left(\mathrm{cm} .{ }^{2}\right)\end{array}$} & \multicolumn{3}{|c|}{ Pre-operative findings } \\
\hline & & & & & & & & \multicolumn{2}{|c|}{$\begin{array}{l}\text { Syst. press. } \\
\text { (mm. Hg) }\end{array}$} & \multirow{2}{*}{$\begin{array}{c}\text { Peak RV-PA } \\
\text { grad. } \\
\text { (mm. Hg) }\end{array}$} \\
\hline & & & RV & Infund. & & & & $\mathbf{R V}$ & PA & \\
\hline $\begin{array}{c}\text { S.K. } \\
15 \\
\text { S.S. } \\
40 \\
\text { L.P. } \\
21 \\
\text { G.H. } \\
10 \\
\text { V.D. } \\
42 \\
\text { T.M. } \\
52 \\
\text { Average } \\
\text { values }\end{array}$ & $\begin{array}{l}\text { Control } \\
\text { Iso. } 1.0 \mu \mathrm{g} . \\
\text { Control } \\
\text { Iso. } 2 \cdot 8 \mu \mathrm{g} . \\
\text { Control } \\
\text { Iso. } 2 \cdot 5 \mu \mathrm{g} \text {. } \\
\text { Control } \\
\text { Iso. } 1.0 \mu \mathrm{g} \text {. } \\
\text { Control } \\
\text { Iso. } 3.0 \mu \mathrm{g} \text {. } \\
\text { Control } \\
\text { Iso. 2.0 } \mu \mathrm{g} . \\
\text { Control } \\
\text { Iso. }\end{array}$ & $\begin{array}{r}76 \\
115 \\
78 \\
120 \\
75 \\
95 \\
84 \\
108 \\
75 \\
95 \\
85 \\
110 \\
79 \\
107\end{array}$ & $\begin{array}{r}23 \\
38 \\
45 \\
145 \\
45 \\
60 \\
27 \\
54 \\
42 \\
55 \\
70 \\
84 \\
42 \\
73\end{array}$ & $\begin{array}{l}17 \\
17 \\
18 \\
25 \\
25 \\
25 \\
17 \\
20 \\
20 \\
20 \\
30 \\
40 \\
21 \\
25\end{array}$ & $\begin{array}{r}6 \\
21 \\
27 \\
120 \\
20 \\
35 \\
10 \\
35 \\
22 \\
35 \\
40 \\
44 \\
21 \\
48\end{array}$ & $\begin{array}{l}4 \cdot 86 \\
7 \cdot 41 \\
3 \cdot 90 \\
6 \cdot 11 \\
4 \cdot 12 \\
5 \cdot 77 \\
6 \cdot 20 \\
9 \cdot 70 \\
4 \cdot 04 \\
5 \cdot 24 \\
5 \cdot 47 \\
5 \cdot 12 \\
4 \cdot 76 \\
6 \cdot 56\end{array}$ & $\begin{array}{l}1.96 \\
1.40 \\
0.83 \\
0.55 \\
0.96 \\
0.82 \\
2.49 \\
1.97 \\
1.18 \\
1.04 \\
0.99 \\
0.76 \\
1.40 \\
1.09\end{array}$ & $\begin{array}{l}156 \\
118^{*} \\
192\end{array}$ & 13 & $\begin{array}{r}180 \\
65 \\
140\end{array}$ \\
\hline
\end{tabular}

PA=pulmonary artery. Other abbreviations as in Table $I . *$ This value not used in calculating the averages. 


\section{Discussion}

The administration of the powerful cardiotonic agent, isoprenaline, resulted in intensification of the subvalvular obstruction to right ventricular outflow in patients with idiopathic hypertrophic subpulmonary stenosis and in patients with hypertrophic subpulmonary stenosis secondary to severe obstruction of the pulmonary valve. In addition, it provoked the development of subpulmonary obstruction in a single patient with subaortic obstruction, who had no obstruction to right ventricular outflow in the basal state. In contrast, it did not attenuate the outflow orifice in patients with congenital valvular pulmonary stenosis or discrete subvalvular stenosis. These observations indicate that muscular obstruction to right ventricular outflow, whether primary in nature, or secondary to valvular stenosis, is dynamic and may vary in severity.

Other investigators have observed that the administration of isoprenaline results in an augmentation of the peak systolic pressure gradient in patients with valvular aortic or pulmonary stenosis (Moss and Quivers, 1963; Moss and Duffie, 1963). Moreover, in some patients who were studied after pulmonary valvulotomy, marked rises in the outflow pressure gradient occurred (Moss and Quivers, 1963). Although the changes in cardiac output induced by the drug were not measured, and determinations of the effects of isoprenaline on the outflow orifice were, therefore, not possible, it now appears likely that the large increases in the pressure gradient that were produced in the latter group

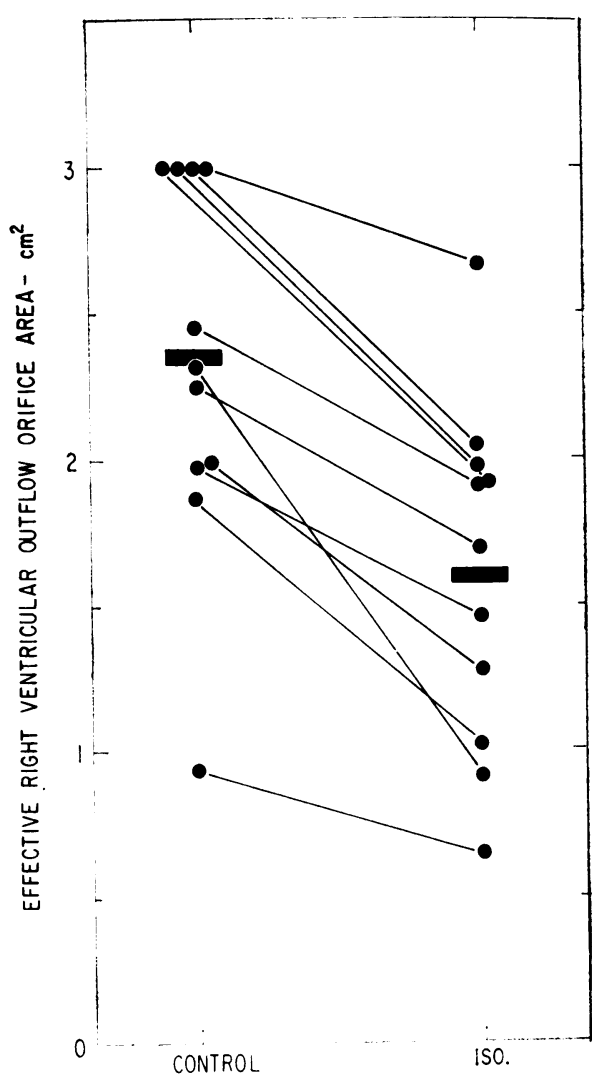

FIG. 1.-Values for the effective right ventricular outflow orifice area during the control period and during the administration of isoprenaline in patients with idiopathic hypertrophic subpulmonary stenosis. The horizontal bars represent the mean values.
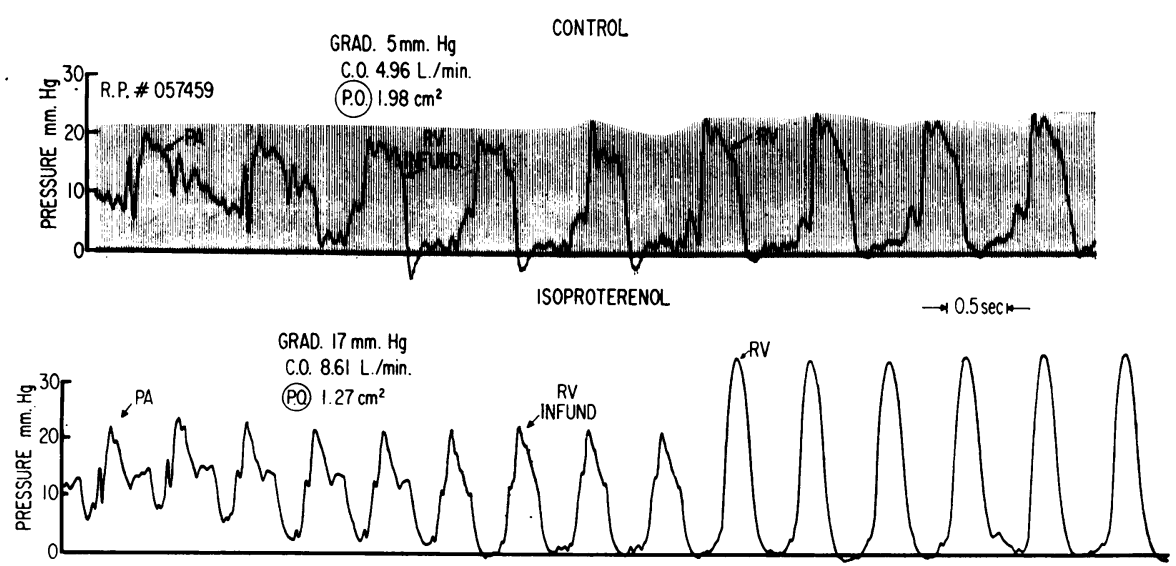

FIG. 2.-Effects of isoprenaline (isoproterenol) in a patient with idiopathic hypertrophic subpulmonary stenosis. Grad.= peak systolic pressure gradient. C.O.= cardiac output. P.O.=effective right ventricular outflow orifice area. $\quad P A=$ pulmonary artery. RV Infund. = right ventricular infundibulum. $R V=$ right ventricle. 

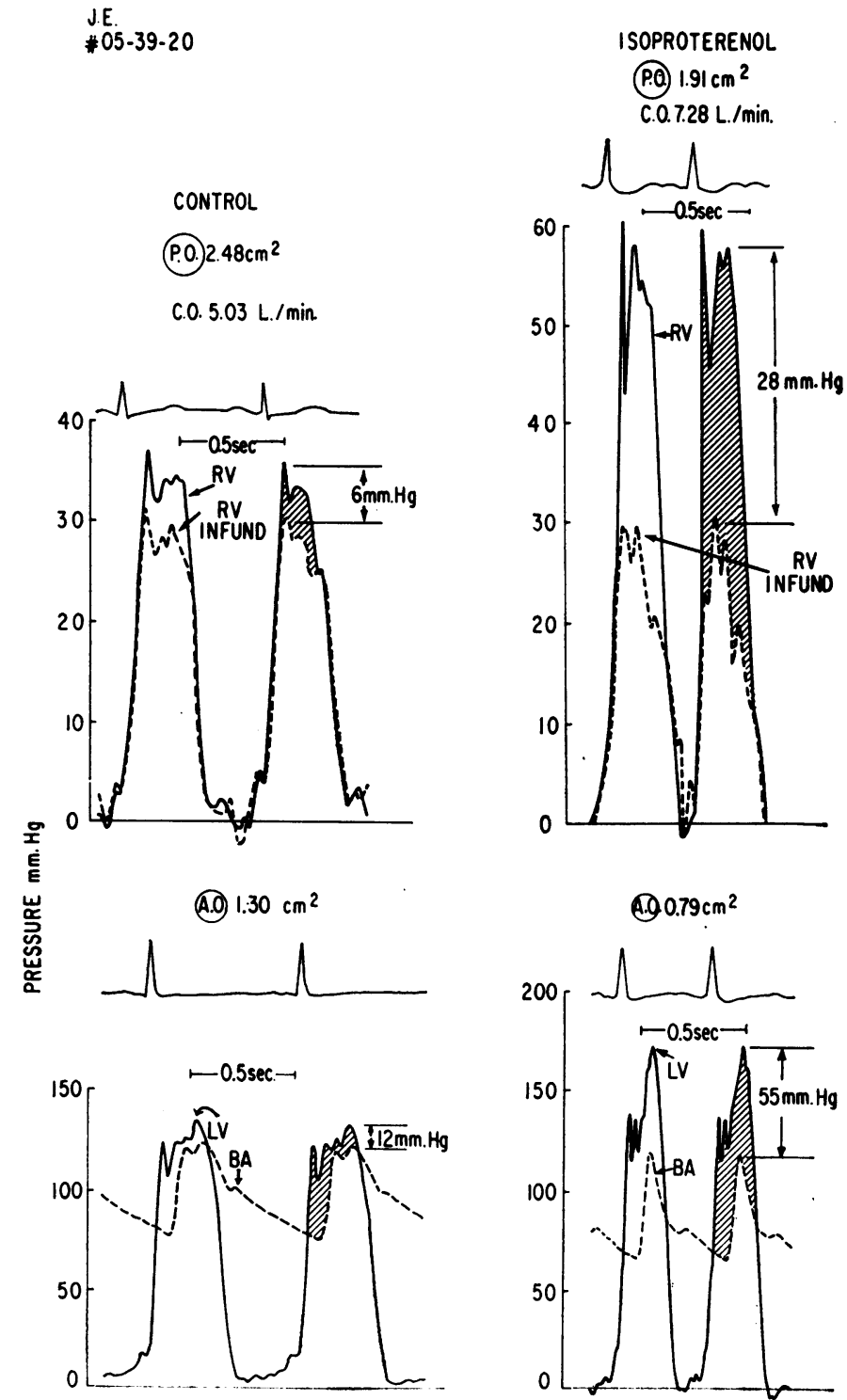

Fig. 3.-Effects of isoprenaline (isoproterenol) in a patient with idiopathic hypertrophic subpulmonary and subaortic stenosis. A.O.=effective left ventricular outflow orifice area. LV=left ventricle, $\mathrm{BA}=$ brachial artery. Other abbreviations as in Fig. 2.

resulted from constriction of the hypertrophied infundibulum in response to the positive inotropic action of the drug. Goodwin et al. (1964) observed that isoprenaline sometimes resulted in increases in pressure gradients across the right ventricular outflow tract in patients with idiopathic hypertrophic subpulmonary stenosis, but the changes were relatively small and determinations of the orifice area were not made.

Little information has, heretofore, been available concerning the fundamental nature of the obstruction to right ventricular outflow in patients with idiopathic hypertrophic subaortic stenosis, though the possibility has been considered that obstruction in the right ventricle is entirely secondary 
TABLE III

Effects of Isoprenaline in Discrete Obstruction to Pulmonary Outflow

\begin{tabular}{|c|c|c|c|c|c|c|c|c|}
\hline \multirow{2}{*}{$\begin{array}{l}\text { Patient } \\
\text { and } \\
\text { age (yr.) }\end{array}$} & \multirow{2}{*}{ Diagnosis } & \multirow{2}{*}{ Condition } & \multirow{2}{*}{$\begin{array}{c}\mathrm{HR} \\
\text { (beats/ } \\
\text { min.) }\end{array}$} & \multicolumn{2}{|c|}{$\begin{array}{l}\text { Syst. press. } \\
\text { (mm. Hg) }\end{array}$} & \multirow{2}{*}{$\begin{array}{c}\text { Peak RV-PA } \\
\text { grad. } \\
\text { (mm. Hg) }\end{array}$} & \multirow{2}{*}{$\begin{array}{c}\text { CO } \\
(1 . / \mathrm{min} .)\end{array}$} & \multirow{2}{*}{$\begin{array}{c}\text { Eff. RV } \\
\text { outflow orif } \\
\left(\mathrm{cm} .{ }^{2}\right)\end{array}$} \\
\hline & & & & $\mathbf{R V}$ & PA & & & \\
\hline $\begin{array}{c}\text { P.L. } \\
11 \\
\text { A.G. } \\
19 \\
\text { J.Y. } \\
17 \\
\text { J.M. } \\
9 \\
\text { P.E. } \\
10 \\
\text { D.S. } \\
6 \\
\text { Average } \\
\text { values }\end{array}$ & $\begin{array}{c}\text { PS } \\
\text { PS } \\
\text { PS } \\
\text { Sub. PS } \\
\text { Sub. PS } \\
\text { Sub. PS }\end{array}$ & $\begin{array}{l}\text { Control } \\
\text { Iso. } 1.2 \mu \mathrm{g} . \\
\text { Control } \\
\text { Iso. } 2.0 \mu \mathrm{g} . \\
\text { Control } \\
\text { Iso. } 1.5 \mu \mathrm{g} . \\
\text { Control } \\
\text { Iso. } 0.8 \mu \mathrm{g} . \\
\text { Control } \\
\text { Iso. } 0.5 \mu \mathrm{g} . \\
\text { Control } \\
\text { Iso. } 0.5 \mu \mathrm{g} . \\
\text { Control. } \\
\text { Iso. }\end{array}$ & $\begin{array}{r}90 \\
126 \\
78 \\
96 \\
100 \\
114 \\
96 \\
104 \\
78 \\
114 \\
90 \\
114 \\
89 \\
111\end{array}$ & $\begin{array}{r}93 \\
127 \\
45 \\
78 \\
94 \\
109 \\
45 \\
55 \\
45 \\
63 \\
28 \\
36 \\
58 \\
78\end{array}$ & $\begin{array}{l}28 \\
28 \\
22 \\
21 \\
12 \\
12 \\
15 \\
20 \\
18 \\
25 \\
18 \\
18 \\
18 \\
21\end{array}$ & $\begin{array}{l}65 \\
99 \\
23 \\
57 \\
82 \\
97 \\
30 \\
35 \\
27 \\
38 \\
10 \\
18 \\
40 \\
57\end{array}$ & $\begin{array}{r}5 \cdot 42 \\
7 \cdot 10 \\
3 \cdot 80 \\
5 \cdot 40 \\
7 \cdot 14 \\
10 \cdot 30 \\
2 \cdot 72 \\
4 \cdot 87 \\
1 \cdot 96 \\
2 \cdot 27 \\
2 \cdot 16 \\
3 \cdot 08 \\
3 \cdot 87 \\
5.50\end{array}$ & $\begin{array}{l}0.61 \\
0.56 \\
0.92 \\
0.84 \\
0.54 \\
0.64 \\
0.63 \\
0.76 \\
0.46 \\
0.38 \\
0.69 \\
0.65 \\
0.64 \\
0.64\end{array}$ \\
\hline
\end{tabular}

$\mathbf{P S}=$ valvular pulmonary stenosis. Sub. PS=subpulmonary stenosis. Other abbreviations as in Tables I and II.

in nature (Oakley, 1964). However, obstructive disease of the right ventricular outflow tract seems clearly to exist not only in association with obstruction to left ventricular outflow, but by itself as well, in the absence of a pressure gradient within the left ventricle. Thus, in a group of 64 patients with IHSS who were reported from this clinic (Braunwald et al., 1964), 10 exhibited right ventricular obstruction in the basal state; in 7 of these 10 patients the obstruction within the left ventricle was more severe than that observed in the right; in 1 the gradients were equal; in 1 the gradient was larger in the right ventricle; and in 1 there was no gradient at all within the left ventricle. Taylor et al.

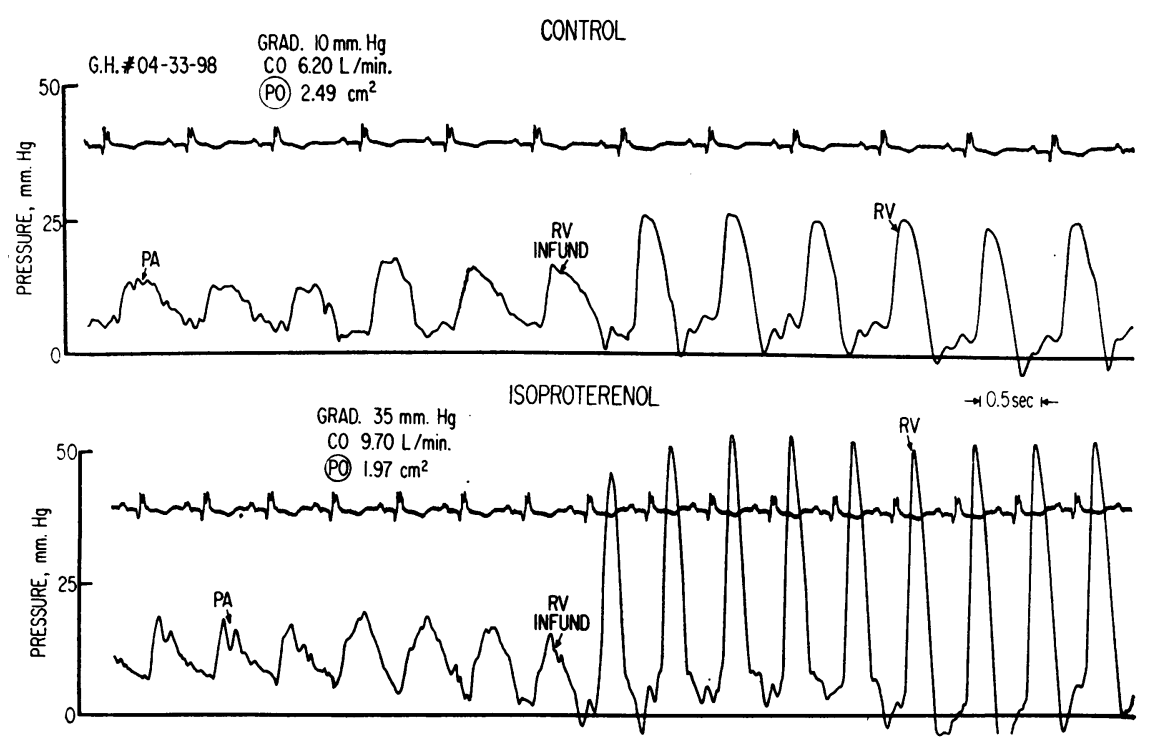

FIG. 4.-Effects of isoprenaline (isoproterenol) in a patient with secondary hypertrophic subpulmonary stenosis. Abbreviations as in Fig. 2. 


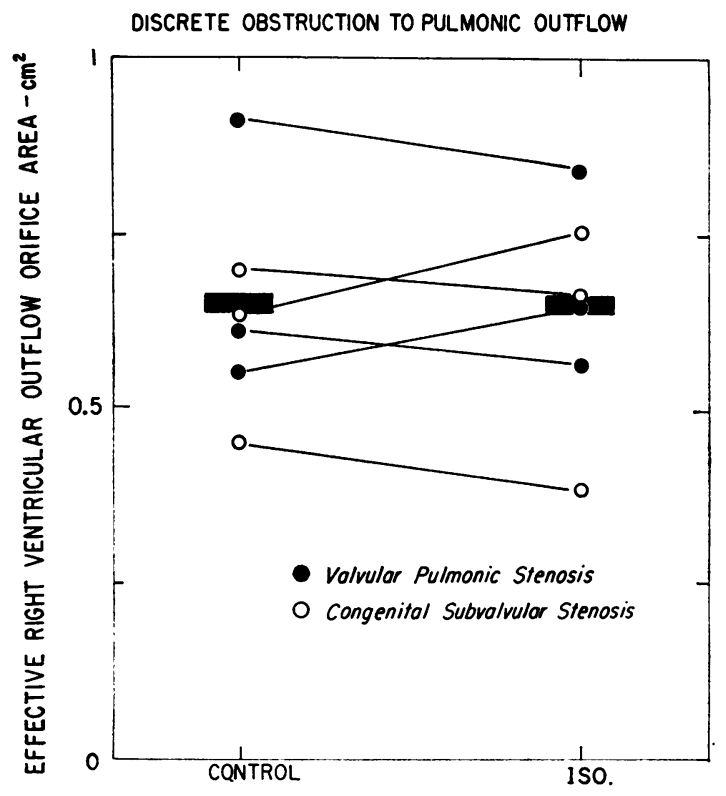

Fig. 5.-Values for the effective right ventricular outflow orifice area during the control period and during isoprenaline infusion in patients with discrete obstruction to pulmonary outflow.
(1964) have also studied one patient having obstruction to right ventricular outflow only. The intensification of obstruction to right ventricular ejection induced by isoprenaline in patients with idiopathic hypertrophic subpulmonary stenosis reported herein suggests that the fundamental nature of the obstructive process is similar in both ventricles, though quantitatively the changes on the right side of the heart produced by the drug are usually not as marked as those on the left. The responses to the drug in this group, as well as in the patients with obstruction to right ventricular outflow following surgical relief of valvular pulmonary stenosis, contrasted with the response of patients with discrete subpulmonary obstruction, and the administration of isoprenaline would, therefore, appear to be a useful diagnostic test for characterizing the nature of subpulmonary obstruction. Furthermore, the response to isoprenaline makes it likely that other interventions that stimulate the contractile state of the myocardium, such as the digitalis glycosides, muscular exercise, as well as interventions

that decrease the end-systolic volume of the right ventricle, such as nitroglycerin, or the Valsalva manœuvre, might also reduce the pulmonary outflow orifice in patients with muscular obstruction to right ventricular outflow, as they do in patients with muscular obstruction to left ventricular outflow (Braunwald et al., 1964).

\section{SUMMARY}

The dynamic nature of the obstruction to ventricular ejection was determined in 23 patients with different forms of obstruction to right ventricular outflow, 20 of whom had hæmodynamic evidence of subvalvular pulmonary stenosis. Cardiac output and right ventricular outflow pressure gradients were recorded, and the effective areas of the outflow tract were calculated before and during infusion of isoprenaline, an agent that stimulates the contractile state of the myocardium. Intensification of the obstruction to right ventricular outflow was observed in 17 of the patients studied. In the 11 patients with idiopathic hypertrophic subpulmonary stenosis, isoprenaline reduced the outflow orifice by an average of $0.75 \mathrm{~cm} .^{2}$ In the 6 patients with secondary hypertrophic subpulmonary stenosis who were studied following successful surgical relief of valvular pulmonary stenosis, isoprenaline reduced the outflow orifice by an average of $0.31 \mathrm{~cm} .^{2}$ No attenuation of the outflow orifice was noted in the 3 patients with valvular pulmonary stenosis nor in the 3 patients with discrete congenital subvalvular stenosis. These observations indicate that muscular obstruction to right ventricular outflow is dynamic, that it can vary in severity depending on the heart's catecholamine background, and that the fundamental nature of the obstructive process is similar in both ventricular outflow tracts. In conclusion, the response to isoprenaline infusion provides a useful test for assessing the nature of subvalvular obstruction to right ventricular outflow. 


\section{REFERENCES}

Braunwald, E., and Ebert, P. A. (1962). Hæmodynamic alterations in idiopathic hypertrophic subaortic stenosis induced by sympathomimetic drugs. Amer. J. Cardiol., 10, 489.

—, Lambrew, C. T., Rockoff, S. D., Ross, J., Jr., and Morrow, A. G. (1964). Idiopathic hypertrophic subaortic stenosis: I. A description of the disease based upon an analysis of 64 patients. Circulation, 30, Suppl. 4, p. 3. , Morrow, A. G., Cornell, W. P., Aygen, M. M., and Hilbish, T. F. (1960). Idiopathic hypertrophic subaortic stenosis: Clinical, hemodynamic and angiographic manifestations. Amer. J. Med., 29, 924.

Brock, R. C. (1955). Control mechanisms in the outflow tract of the right ventricle in health and disease. Guy's Hosp. Rep., 104, 356.

Goodwin, J. F., Hollman, A., Cleland, W. P., and Teare, D. (1960). Obstructive cardiomyopathy simulating aortic stenosis. Brit. Heart J., $22,403$.

—, Shah, P. M., Oakley, C. M., Cohen, J., Yipintsoi, T., and Pocock, W. (1964). The clinical pharmacology of hypertrophic obstructive cardiomyopathy. In Ciba Foundation Symposium: Cardiomyopathies, ed. G. E. W. Wolstenholme and M. O'Connor, p. 189. Churchill, London.

Gorlin, R., and Gorlin, S. G. (1951). Hydraulic formula for calculation of the area of the stenotic mitral valve, other cardiac valves, and central circulatory shunts. Amer. Heart J., 41, 1.

Kirklin, J. W., Connolly, D. C., Ellis, F. H., Jr., Burchell, H. B., Edwards, J. E., and Wood, E. H. (1953). Problems in the diagnosis and surgical treatment of pulmonic stenosis with intact ventricular septum. Circulation, 8, 849.

Krasnow, N., Rolett, E., Hood, W. B., Jr., Yurchak, P. M., and Gorlin, R. (1963). Reversible obstruction of the ventricular outflow tract. Amer. J. Cardiol., 11, 1.

Moss, A. J., and Duffie, E. R. (1963). The use of isoproterenol (Isuprel) in the evaluation of congenital cardiac defects. Circulation, 27, 51 .

- , and Quivers, W. W. (1963). Use of isoproterenol in the evaluation of aortic and pulmonic stenosis. Amer. J. Cardiol., 11, 734.

Oakley, C. M. (1964). Discussion. In Ciba Foundation Symposium: Cardiomyopathies, ed. G. E. W. Wolstenholme and M. O'Connor, p. 93. Churchill, London.

Taylor, R. R., Bernstein, L., and Jose, A. D. (1964). Obstructive phenomena in ventricular hypertrophy. Brit. Heart J., 26, 193.

Whalen, R. E., Cohen, A. I., Sumner, R. G., and McIntosh, H. D. (1963). Demonstration of the dynamic nature of idiopathic hypertrophic subaortic stenosis. Amer. J. Cardiol., 11, 8.

Wigle, E. D. (1964). Discussion. In Ciba Foundation Symposium: Cardiomyopathies, ed. G. E. W. Wolstenholme and M. O'Connor, p. 224. Churchill, London. 